2. Each of the calcium salts was found to interfere with the utilization of iron as reflected by liver iron stores, haemoglobin regeneration and increase in heart weight.

3. The two phosphates had no significant effect on either the iron content of the liver or on the rate at which haemoglobin was regenerated.

4. The interference caused by the calcium salts is discussed on the basis that the 'mucosal block' may be operating to prevent the absorption of iron.

The authors wish to acknowledge the valuable technical assistance provided by Miss Rita Seguin and Mrs Odette Milstone in the preparation of diets, the care of the experimental animals and the analyses of livers and diets, and to express their thanks to Mr E. R. W. Gregory for supplying the experimental animals, and to Miss C. E. Cox for advice about the statistical treatment of results.

\title{
REFERENCES
}

Chapman, D. G. \& Campbell, J. A. (1957). Brit. F. Nutr. I1, I 7 .

Granick, S. (1946). F. biol. Chem. 164, 737 .

Greig, W. A. (1952). Brit. F. Nutr. 6, 280.

Kletzien, S. W. (I935). F. Nutr. 9, suppl., p. 9.

Kletzien, S. W. (1938). F. Nutr. 15, suppl., p. I6.

Kletzien, S. W. (1940). F. Nutr. 19, I87.

McCoy, R. H. (1949). In The Rat in Laboratory Investigation, and ed. p. 68. [E. J. Farris and J. Q. Griffith, editors.] London: J. B. Lippincott Co.

Pharmacopoeia of the United States of America, Fourteenth Revision (1950). Easton, Pa., U.S.A.: Mack Publishing Company.

\section{Effect of bone meal in enriched flour on the utilization of iron by anaemic and normal rats}

\author{
By D. G. CHAPMAN AND J. A. CAMPBELL \\ Food and Drug Laboratories, Department of National Health and Welfare, \\ Ottawa, Canada
}

(Received 3r Fuly 1956-Revised I4 January 1957)

Chapman \& Campbell (1957 $a, b)$ have shown that small amounts of edible bone meal added to patent unenriched flour, baked into bread and fed to anaemic rats have no effect on iron utilization. If, however, relatively large amounts of bone meal, calcium carbonate or other calcium salts were added to diets containing small amounts of iron, the utilization of iron was upset, as reflected by liver iron storage and haemoglobin regeneration. The amounts of calcium carbonate or edible bone meal added were approximately five times the amount permitted by the Canadian Regulations under the Food and Drugs Act for enriched bread, which require the addition of 'calcium carbonate or edible bone meal in an amount that will provide in one pound of enriched flour not less than 500 milligrams and not more than $65^{\circ}$ milligrams of calcium' (Office Consolidation of the Food and Drugs Act and of the Food and Drug Regulations, 1954). Pett (1952) has reported that bone meal in enriched flour resulted in anaemia in children. 
It is the purpose of this paper to report the effect, on both anaemic and normal rats, of diets containing $80 \%$ dried bread baked from commercial flours that were unenriched, enriched with vitamins and iron, or enriched with vitamins, iron and bone meal.

\section{EXPERIMENTAL}

The methods of analysis and techniques used in this study were similar to those described previously (Chapman \& Campbell, I957a). Both normal and anaemic 35 -day-old Wistar rats were employed. The normal rats were maintained on the regular stock diet used in the animal colony until they were placed on test.

Each of the three types of flour (milled from the same lot of wheat), unenriched, enriched and enriched with bone meal added, was obtained from two Canadian milling companies and was baked into bread, dried and fed, as $80 \%$ of the diet, to the rats. The balance of the diet was made up of the basal ration as previously reported (Chapman \& Campbell, I957a). Ten rats, five male and five female, were kept on test on each diet for 20 weeks.

\section{RESULTS}

The analyses of the diets prepared from the three flours are shown in Table I. Unenriched flour A contained less iron than unenriched flour B, so that the diet prepared from flour A contained $2 \cdot 78 \mathrm{mg}$ iron/ $100 \mathrm{~g}$ and the diet prepared from flour B $3.86 \mathrm{mg}$ / I00 g. The calcium and phosphorus contents of the diets prepared from the two flours were similar. As in the earlier experiments, a $\mathrm{Ca}: \mathrm{P}$ ratio of $2 \cdot 0$ was obtained.

Table 1. Analysis of diets made from bread baked from unenriched flour, enriched flour or enriched flour with bone meal

\begin{tabular}{|c|c|c|c|c|c|}
\hline Type of flour & $\begin{array}{c}\mathrm{Fe} \\
(\mathrm{mg} / \mathrm{x} 00 \mathrm{~g})\end{array}$ & $\begin{array}{c}\mathrm{Ca} \\
(\mathrm{mg} / 100 \mathrm{~g})\end{array}$ & $\underset{(\mathrm{mg} / \mathrm{I} O 0 \mathrm{~g})}{\mathbf{P}}$ & $\begin{array}{l}\text { Ratio, } \\
\text { Ca:P }\end{array}$ & $\begin{array}{l}\text { Ratio, } \\
\mathrm{Ca}: \mathrm{Fe}\end{array}$ \\
\hline \multicolumn{6}{|c|}{ Flour A } \\
\hline ched & $2 \cdot 78$ & 3 I 5 & 155 & $2 \cdot 0$ & I 13 \\
\hline hed & $5 \cdot 33$ & 305 & I $5 \mathrm{I}$ & $2 \cdot 0$ & 57 \\
\hline thed, with bone meal & $5 \cdot 22$ & 414 & 202 & $2 \cdot 0$ & 79 \\
\hline \multicolumn{6}{|c|}{ Flour B } \\
\hline$d^{*}$ & $3 \cdot 86$ & $32 \mathrm{I}$ & 150 & $2 \cdot I$ & 83 \\
\hline & $5 \cdot 34$ & 312 & 147 & $2 \cdot I$ & 58 \\
\hline d, with bone meal & $5 \cdot 45$ & 384 & 192 & $2 \cdot 0$ & 70 \\
\hline
\end{tabular}

The effect of enrichment of the flours on food consumption, gain in body-weight, iron content of liver, and heart weight is shown in Table 2 for normal rats and in Table 3 for anaemic rats.

The enrichment did not influence the amounts of food consumed by, or the gains in weight of, normal rats fed on either flour A or B. With flour A enrichment resulted in a significant increase in liver iron compared with that from unenriched flour. The presence of bone meal in the flour, however, had no significant effect on the iron content of the liver. When flour B was fed, the enriched flours did not cause a significant increase in the iron content of the livers over those with the unenriched flour. This result was undoubtedly due to the higher iron content of the unenriched flour $\mathrm{B}$ 
Table 2. Effect of breads baked from commercial flours on food consumption, gain in body-weight, iron content of liver and heart weight of normal rats

(Mean values with their standard errors for groups of five male or five female rats)

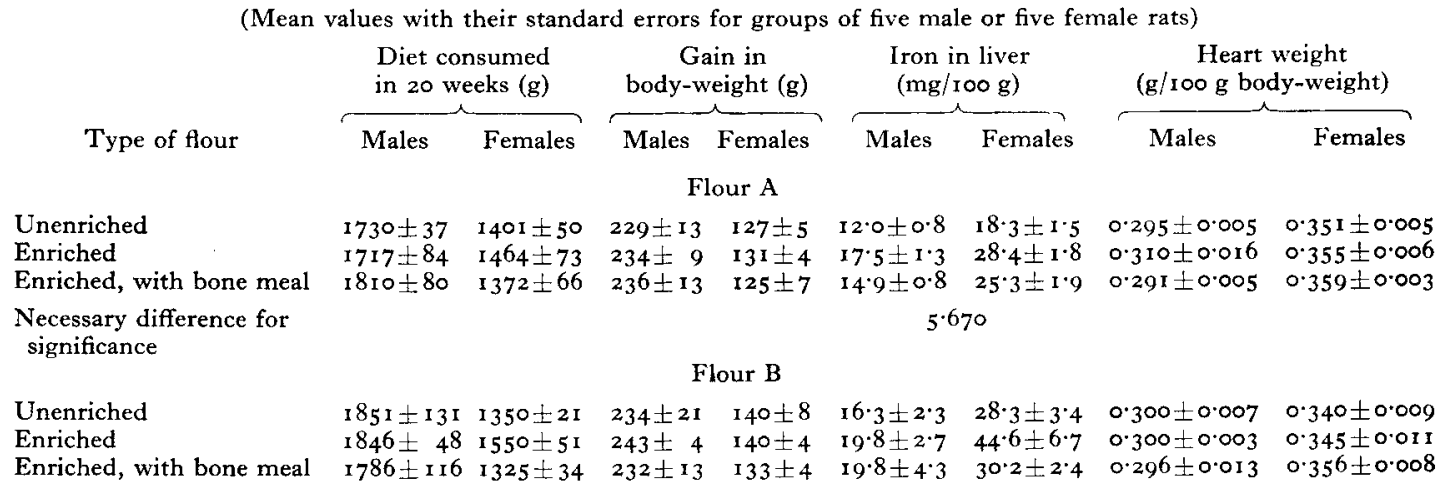

Table 3. Effect of breads baked from commercial flours on food consumption, gain in body-weight, iron content of liver and heart weight of anaemic rats

(Mean values with their standard errors for groups of five male or five female rats)

\begin{tabular}{|c|c|c|c|c|c|c|c|c|}
\hline \multirow[b]{2}{*}{ Type of flour } & \multicolumn{2}{|c|}{$\begin{array}{l}\text { Diet consumed } \\
\text { in } 20 \text { weeks }(g)\end{array}$} & \multicolumn{2}{|c|}{$\begin{array}{c}\text { Gain in } \\
\text { body-weight }(\mathrm{g})\end{array}$} & \multicolumn{2}{|c|}{$\begin{array}{l}\text { Iron in liver } \\
(\mathrm{mg} / \mathrm{I} 00 \mathrm{~g})\end{array}$} & \multicolumn{2}{|c|}{$\begin{array}{c}\text { Heart weight } \\
\text { (g/roo g body-weight) }\end{array}$} \\
\hline & Males & Fen & Males & Females & Males & Females & Males & Females \\
\hline \multicolumn{9}{|c|}{ Flour A } \\
\hline Unenriched & $1484 \pm 52$ & $1346 \pm 129$ & $223 \pm 14$ & $145 \pm 2$ & $7 \cdot 5 \pm 0.7$ & $10 \cdot 5=$ & $0.311 \pm 0$ & $0.34^{8} \pm 0.004$ \\
\hline Enriched & I $538 \pm 62$ & $1352 \pm 129$ & 219 士 14 & 145 & $x 4.9 \pm 1 \cdot I$ & $32 \cdot 6$ & $=0.003$ & 0.352 \\
\hline Enriched, with & $1372 \pm 31$ & $1328 \pm 28$ & $201 \pm 14$ & $142 \pm 7$ & $147 \pm 1 \cdot 4$ & $21 \cdot 1 \pm 2 \cdot 1$ & $0.329 \pm 0.010$ & $0.347 \pm 0.008$ \\
\hline \multicolumn{9}{|c|}{ Flour B } \\
\hline $\begin{array}{l}\text { Unenriched } \\
\text { Enriched } \\
\text { Enriched, with bone meal }\end{array}$ & $\begin{array}{l}1702 \pm 9 I \\
1984 \pm 5 I \\
1806 \pm 53\end{array}$ & $\begin{array}{l}1589 \pm 111 \\
1471 \pm 68 \\
1528 \pm 70\end{array}$ & $\begin{array}{l}266 \pm 13 \\
281 \pm 4 \\
305 \pm 10\end{array}$ & $\begin{array}{l}172 \pm 8 \\
153 \pm 13 \\
160 \pm 7\end{array}$ & $\begin{array}{l}15 \cdot 6 \pm 1 \cdot 5 \\
17.4 \pm x \cdot 3 \\
18 \cdot 6 \pm 0.8\end{array}$ & $\begin{array}{l}29 \cdot 9 \pm 4 \cdot 8 \\
33 \cdot 3 \pm 4 \cdot 2 \\
29 \cdot 6 \pm 4 \cdot 5\end{array}$ & $\begin{array}{l}0.303 \pm 0.003 \\
0.298 \pm 0.005 \\
0.288 \pm 0.003\end{array}$ & $\begin{array}{l}0.350 \pm 0.009 \\
0.354 \pm 0.012 \\
0.363 \pm 0.009\end{array}$ \\
\hline
\end{tabular}

compared with the unenriched flour A. As with flour A, the presence of bone meal in flour B had no significant effect on the iron content of the livers. The enrichment of either flour A or flour B in the presence or absence of bone meal had no significant effect on heart weight.

The effects of the three types of flours on haemoglobin level in normal rats are shown in Fig. $I$ for both flour A and flour B, where it can be seen that the unenriched flour A regenerated haemoglobin at a slower rate than did flour B. This difference was undoubtedly due to the higher iron content of flour B. In neither flour A nor flour B did the presence of bone meal in the enriched flour have any effect upon the rate at which haemoglobin was regenerated in normal rats. At the same time, the enriched flours, with or without bone meal, regenerated haemoglobin more rapidly than did the unenriched flours.

An analysis of variance of the results for anaemic rats indicated that with diets containing either flour A or flour B there was no significant effect on food consumption, on gain in body-weight or on heart weight. With flour A there was a significant diet $\times$ sex interaction in the iron content of the livers. When this interaction was used as the error term, the overall effect of the diets on the iron content of the liver became 
insignificant. On the other hand, when flour $B$ was used, the enrichment did not result in any significant increases in liver iron. The presence of bone meal in either flour had no significant effect on the iron content of the livers.

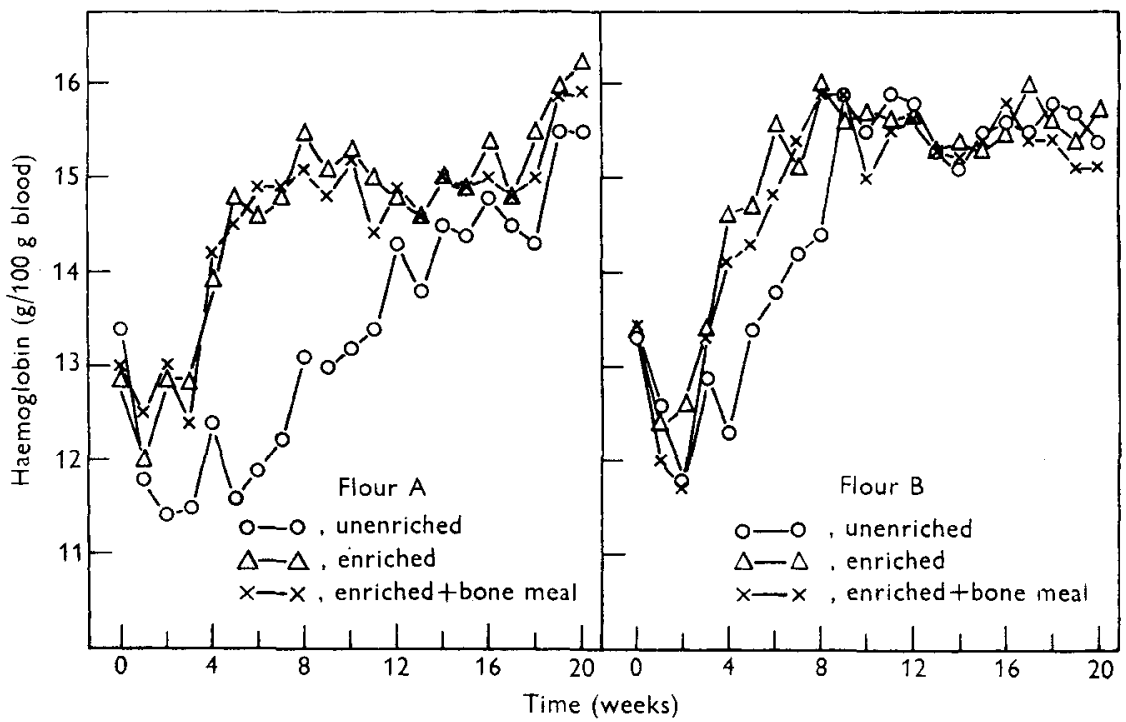

Fig. I. Effect of unenriched flour, enriched flour and enriched flour with bone meal on haemoglobin level in normal rats.

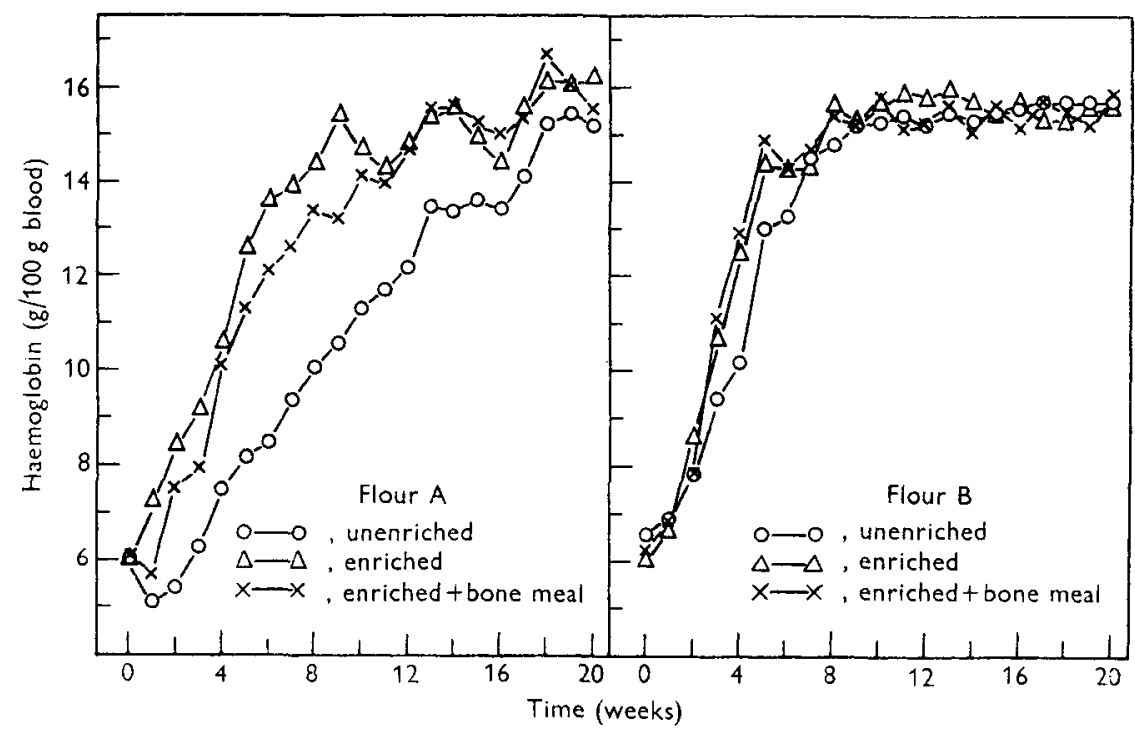

Fig. 2. Effect of unenriched flour, enriched flour and enriched flour with bone meal on haemoglobin regeneration in anaemic rats.

The effect on haemoglobin regeneration of feeding the three types of flour to anaem ic rats is shown in Fig. 2, where again it can be seen that the enriched flours we re superior to the unenriched and also that the presence of bone meal had no apprecia ble effect on haemoglobin level. 


\section{DISCUSSION}

Pett (1952) reported that boarding-school children became anaemic when bone meal was added to the flour used in their diets. He concluded: 'If enriched flour [containing bone meal] caused the increase in anemia that was found, the explanation may rest in an interference with iron absorption by the calcium or phosphate in the added bone meal. If enriched flour did not cause the increase in anemia, the fact remains that no beneficial effect was observed from the iron in enriched flour.' In 1948 it became obligatory to add bone meal to all flour used in Newfoundland, and a survey carried out in 1952 showed no reduction in the haemoglobin levels. In commenting on this, Jolliffe (I952) has stated: 'This indicates to me that the addition of bone meal to the enriched flour has led to no decrease in absorption of the blood iron.'

The values for the iron contents of the livers of both normal and anaemic rats, shown in Tables 2 and 3 suggest that the presence of bone meal leads to a decrease in the iron content of the liver. These apparent decreases, however, did not reach significance at the usual $P=0.05$ level.

Besides the fact that under the conditions of our experiment the presence of bone meal in the enriched flour had no significant adverse effect on the utilization of iron, it should be mentioned that it appeared to lead to gains in weight, expressed per unit of food consumed, equal to or greater than those obtained in the absence of bone meal. These increases in gains in weight due to the presence of bone meal, however, did not reach significance.

\section{SUMMARY}

I. Groups of ten (five male and five female) anaemic and normal rats have been fed for 20 weeks on dried bread baked from unenriched flour, flour enriched with vitamins and iron, and flour enriched with vitamins, iron and bone meal.

2. When fed as $80 \%$ of the diet to either normal or anaemic rats, the enriched breads regenerated haemoglobin more rapidly than did unenriched breads.

3. The presence of bone meal in enriched bread fed as $80 \%$ of the diet had no significant adverse effect on either liver storage of iron or haemoglobin regeneration in either normal or anaemic rats.

The authors wish to acknowledge the valuable technical assistance provided by Miss Rita Seguin and Mrs Odette Milstone in the preparation of diets, the care of the experimental animals and the analyses of livers and diets, and to express their thanks to Mr E. R. W. Gregory for supplying the experimental animals and to Miss C. E. Cox for advice about the statistical treatment of the results.

\section{REFERENCES}

Chapman, D. G. \& Campbell, J. A. (1957a). Brit. F. Nutr. I1, II7.

Chapman, D. G. \& Campbell, J. A. (1957b). Brit. F. Nutr. II, 127.

Joliffe, N. (1952). Personal communication.

Pett, L. B. (1952). Fed. Proc. rr, 453.

Office Consolidation of the Food and Drugs Act and of the Food and Drug Regulations (1954). Ottawa, Canada: Queen's Printer. 